solved, the other set may be reduced to quadratures. If the axis of moment of momentum is fixed, the complete solution is by quadrature, thus paralleling the gravitational problem.

It also appears that Lagrange's investigations in the problem of three bodies are generally independent of the law of gravitation. For example, those motions in which the triangle of the bodies is always similar to itself require that triangle to be either equilateral or with collinear vertices, and the sides to revolve in a fixed plane through the center of gravity. It is shown here that the angular velocity of the triangle varies inversely as the square of a side and so is constant for rigid configurations. Also that no other solution than the above is possible for constantly collinear bodies whose co-line is not a fixed line.

Lagrange's biquadratic equation for $\rho$ holds also for arbitrary motion, and his differential equation for the same in any gravitational motion has the roots of that biquadratic for particular, and not singular, solutions.

H. E. Slaught, Secretary of the Section.

\title{
JOINT MEETINGS OF MATHEMATICIANS AND ENGINEERS AT THE UNIVERSITY OF CHICAGO.
}

A SERIES of meetings of mathematicians and engineers was held at the University of Chicago, December 30-31, 1907, under the auspices of the Chicago Section of the AMERICAN Mathematical Society and conjointly with Sections A (mathematics and astronomy) and D (mechanical science and engineering) of the American Association for the Advancement of Science.

The invitation to join in the discussion of the teaching of mathematics to students of engineering had been widely distributed among those engaged in the practice of engineering as well as among professors in technical schools. The attendance was large and representative, including one hundred men especially interested on the mathematical side and fifty on the engineering side. Among the institutions represented were the State Universities of Illinois, Indiana, Iowa, Kansas, Minnesota, Missouri, Nebraska, Ohio, Pennsylvania, Vermont, 
West Virginia and Wisconsin; the following technical schools: Armour Institute of Technology, Bradley Polytechnic Institute, Case School of Applied Science, Lewis Institute of Chicago, Massachusetts Institute of Technology, Michigan College of Mines, Michigan Agricultural College, Purdue University, Rose Polytechnic Institnte, Stevens Institute of Technology, and the Agricultural and Mechanical College of Texas; and the following institutions: Brown University, The Carnegie Institution of Washington, University of Chicago, University of Cincinnati, Colgate University, Harvard University, Knox College, Miami University, James Millikin University, Kalamazoo College, New Hampshire College, Oberlin College, Ohio Wesleyan University, University of the South, Union College, Washington University, Wheaton College, and the United States Weather Bureau.

The promotion of acquaintance and good fellowship was an important feature of the meetings, which was fostered by the admirable arrangements provided by the University of Chicago and especially by the subscription dinner attended by one hundred engineers and mathematicians. The speakers at the dinner, introduced by Professor E. B. Van Vleck, Chairman of the Chicago Section of the American Mathematical Society, were Professor Calvin M. Woodward, Dean of the School of Engineering of Washington University, St. Louis, Mo., Mr. Charles F. Scott, Chief Consulting Engineer of the Westinghouse Electric and Manufacturing Company, Pittsburgh, Pa., Professor George A. Swain, Massachusetts Institute of Technology, Boston, Mass., and Professor Edward V. Huntington, Harvard University, Cambridge, Mass.

The presentation of the papers, covering two half days, led to an enthusiastic discussion which extended to a third session and which culminated in the appointment of a committee to take into consideration the whole question of the mathematical curriculum in technical schools and in technical departments of colleges and universities, and to report to a joint meeting of engineers and mathematicians to be held in 1909 in connection with the annual gathering of the Society for the promotion of engineering education. The selection of this important committee was entrusted to Professor E. V. Huntington of Harvard University, Professor Gardner S. Williams of the University of Michigan, and Professor E. J. Townsend of the University of Illinois, who themselves are to constitute the nucleus of 
the committee and who were given full power to select the remaining members, choose a chairman, and determine the scope of the investigation to be entered upon, it being understood that the committee shall number not less than fifteen and shall be widely representative both geographically and as to all the institutions and interests involved.

At the first session four papers were presented as follows :

"The present status of mathematical instruction for engineers in American schools," Professor E. J. Townsend, University of Illinois.

"The present status of mathematical instruction for engineers in foreign schools," Professor ALEXANDER ZIWET, University of Michigan.

"The print of view in teaching engineering mathematics," President R. S. Woodward, The Carnegie Institution of Washington.

"The scope and spirit of mathematical instruction for engineers," Mr. Charles F. Scotr, consulting engineer, Westinghouse Electric and Manufacturing Company.

The second session consisted of a symposium on the topic: "What is needed in the teaching of mathematics to students of engineering?" The subdivisions of the topic were :

(a) What range of subjects? (b) To what extent in the various subjects? (c) By what methods of presentation? (d) What should be the chief aims?

The speakers, who represented three phases of the subject, namely, (1) the standpoint of the practicing engineer, (2) the standpoint of the professor of engineering, (3) the standpoint of the professor of mathematics in the engineering school, were as follows :

RAlpH Modjeski, consulting civil engineer, Chicago, Ill.

Charises S. Sischter, professor of applied mathematics and consulting engineer, University of Wisconsin.

GaRdNer S. WILlIAMs, professor of civil hydraulic and sanitary engineering and consulting engineer, University of Michigan.

Frederick S. Woods, professor of mathematics, Massachusetts Institute of Technology, Boston, Mass.

George F. Swain, professor of civil engineering, Massachusetts Institute of Technology, Boston, Mass.*

* Professor Swain, on short notice, supplied the place of Mr. W. L. Abbott, chief operating engineer of the Chicago Edison Company, who was unexpectedly unable to be present. 
Arthur N. Talbot, professor of municipal and sanitary engineering in charge of theoretical and applied mechanics, University of Illinois.

Fred. W. McNaIr, president of the Michigan College of Mines, Houghton, Mich.

J. A. L. WADDELL, consulting bridge engineer, Kansas City, Mo., whose paper was read by Professor O. D. Kellogg.

The papers will be printed in full during the year 1908 in Science and will thus reach all who are members of the American association for the advancement of science.

Abstracts of the papers and a list of those who contributed to the general discussion are given below :

Professor Townsend considers the rapidly increasing demand for trained men in the field of engineering and the remarkable growth in recent years of the technical schools, both in number and in equipment and efficiency, and shows that the time is indeed ripe for serious consideration, on the part of both mathematicians and engineers, of all phases of the question of mathematical training for engineering students. He has selected for comparison seventeen institutions in this country where engineering training is either an important or the exclusive feature and he considers three questions with respect to the mathematical training of engineering students in these institutions, as representative of the status in the country at large ; namely, (1) the entrance requirements, (2) the requirements for graduation, (3) the qualifications of the instructional force. Under the first and second of these heads Professor Townsend exhibits a comparative tabular statement and draws a number of incisive conclusions both as to the facts and as to the tendencies, all of which may well be pondered carefully by everyone interested in the industrial and scientific development in America. These data and preliminary observations will be of prime importance to the committee of fifteen who are to investigate and report upon the whole question of the mathematical curriculum in the technical schools. Under the third head also Professor Townsend has clearly set forth the difficulties and the demands of the situation, and it will be the province of the general committee to report also upon these matters. It is greatly to be desired that all mathematicians may not only read this paper, as it will appear in full in Science, but that many suggestions may be communicated to the committee through Professor Town- 
send. To this end the following questions suggested by his paper are proposed:

\section{Entrance Requirements.}

1. Is a greater uniformity of entrance requirements desirable?

2. Most colleges in the middle west admit on certificate from accredited schools. In addition to this should engineering students be required to pass an entrance examination in algebra, with the understanding that if they fail to make satisfactory grade, more than the usual amount of work must be done to secure credit in college algebra?

3. Should a knowledge of logarithms and the plotting of simple algebraic curves be added to the entrance requirements?

4. Should the standard of admission be raised so as to include trigonometry and college algebra?

5. Should the requirements be made to cover less ground and be correspondingly intensified?

6 . Should more attention be paid to analytic and formal work, particularly in arithmetic and algebra?

7. Should a year of work in mathematics and science of college grade be required for entrance, or should the college course be extended to five years?

\section{Requirements for Graduation.}

1. What should be the relative length of time spent on algebra, trigonometry, analytical geometry, and calculus ?

2. Which should precede, algebra or trigonometry?

3. What topics should be particularly emphasized in college algebra? in calculus?

4. How far ought the instruction of the first two years' work in mathematics to be made "practical"; how far should we insist upon rigorous demonstrations of principles taught?

5 . Should students in one line of engineering, say civil engineering, be given problems of a different nature than those given to students in other lines, say mechanical or electrical engineering?

6. Should differential equations and least squares be required subjects in any engineering course? If so, how extensive should these courses be?

7. Should we have a separate course on "applications" having for its purpose the cultivation of ability for rapid com- 
putation and the use for engineering work of such instruments as the slide rule, planimeter, integraph, computing machines, etc.?

8. What opportunity for the study of pure mathematics should be given the engineering student beyond the usual course in calculus? What courses might be made elective in the junior or senior years?

9. Should a first course in mechanics be given to engineering students in the freshman year and before the student has had calculus?

\section{Administrative Questions.}

1. What qualifications should we insist upon for the instructor of engineering students in mathematics?

2. How much elementary mechanics should be taught in connection with the calculus? Should this elementary mechanics be taught by the mathematical department?

3 . Should the work in descriptive geometry be made more mathematical in treatment? Should it be taught by the mathematical department?

4. What can be done in general to bring about a closer relation between the teachers of mathematics and the teachers of engineering?

Professor Ziwet refers to the fact that remarkable and characteristic developments have taken place in England and Scotland, and that France represents probably the highest standard of any country with respect to mathematical training for engineering students, requiring, for instance, for admission to the Ecole polytechnique almost as much mathematics as would be required for graduation from our technical colleges. He considers, however, in some detail only the technical curricula of the German schools with which he is personally familiar, and reaches the general conclusion that while the average German engineer may ultimately know no more mathematics than the average American engineer, yet an able German student in his technische Hochschule, or engineering university, can get a more thorough scientific equipment than an equally able American student in his alma mater. One important advantage in the training of the German student is the fact that his preparatory mathematics (including arithmetic) is distributed systematically and continuously over a period of nine years, whereas in American schools there is much discontinuity and lack of homogeneity 
all along the line from the grammar school through the high school and freshman and sophomore years of the college course. Professor Ziwet gives an excellent resumé of the three phases of reform in the teaching of mathematics which are now commanding attention; namely, one which was originated by the German association of engineers, one which was promulgated by the university authorities, and a third which was proposed in connection with the committee of the German association of Naturforscher and Aertzte. From all these considerations Professor Ziwet draws thoughtful conclusions as to the situation in America and suggests some timely notes of warning.

President Woodward maintains that the fundamental ideas which belong to mathematics and mathematical physics and which form an essential part of engineering training are more inherently difficult than we commonly suppose, and that failure to recognize this in our teaching is the most glaring fault. We marvel at the ease with which the student forgets or fails to comprehend what we try to teach him. We must expect this and must therefore patiently continue to insist upon attention to the fundamental and elementary notions, and drive them home by unremitting practice in computational applications. President Woodward would have most of our text-books remodelled so as to present first the plain statement of facts and much later the theoretical and abstruse considerations. He takes pride in the high development in this country of pure mathematics and of experimental physics, but deplores the conspicuous lack of men highly trained in both mathematics and physics such as the French have produced - who combine both the theoretical and the practical and who therefore are prepared to advance the standards of scientific attainment in engineering lines. $\mathrm{He}$ attributes the dearth of such men in the theoretical field and in the teaching profession to the alluring remunerations held out to those who enter the commercial side of engineering work. President Woodward finds great hope for the future in this cooperation of mathematicians and engineers which has been inaugurated in these joint meetings and which bids fair to be perpetuated and extended through the mutually cordial sentiment here expressed and especially through the forces here put into operation.

Mr. Scott's paper presents many points for serious consideration to the teacher of pure mathematics. He appreciates fully 
the theoretical point of view with respect to the training of an engineer, yet he is in a position to realize how intensely practical the average engineer must be and how little use he has for any mathematics which he cannot instantly translate into the terms of his work-a-day environment. At the outset he discusses three questions: What are the uses to which an engineer may apply mathematics? What kind of mathematics does he need? What skill does he require in the use of mathematics? He then proceeds to discuss what mathematical subject matter should be covered by a student of engineering and how it should be taught. In this connection he lays great stress upon the training of the judgment and the development of the mathematical sense. It is one thing to know higher mathematics, or mathematics of any kind, and quite another thing to know how to use this knowledge in the practical world in bringing things to pass. "The ability to state a problem, to recognize the elements which enter into it, to see the whole problem, not overlooking some important factor, to use good judgment as to the reliability of the data involved, to be able to interpret the result, to recognize its physical significance - such powers as these are of higher order and of greater significance to the engineer than the ability to take a stated problem and work out the answer. It may be said that this is not strictly mathematics, but it is just the judgment and insight which make mathematics really useful and effective." Mr. Scott concludes with a paragraph on the relation of education to the affairs of life which every teacher of mathematics may well ponder.

Mr. Modjeski speaks from the standpoint both of a man highly trained in the Ecole des Ponts et Chaussées of France and also of a highly successful consulting bridge engineer of Chicago. While he would in no wise depreciate the stimulating effect of the mental discipline derived from a broad general course in the higher mathematics, he would call attention to the present agitation in France and Germany, especially in France, looking toward the curtailment of the current mathematical program in the engineering schools, on the ground that it is unnecessarily extensive, considerably more so than in this country. Mr. Modjeski would raise the question as to whether we should not specialize the mathematical courses and select for each branch of engineering those particularly adapted to training in that line. For instance, a railroad engineer who aspires to 
become a railroad official requires less knowledge of the calculus than the electrical or bridge engineer, but on the other hand he requires a greater knowledge of geology and common law than either of these. The bridge engineer demands a higher mathematical training than any other branch of the profession, and yet such a course as the theory of differential equations will be of little if any use to him and his time might better be given to such a course as, for instance, the methods of least work, which no bridge engineer should neglect. Mr. Modjeski would advocate the replacing of the abstract and meaningless problems of the elementary text-books by problems of a more practical and interesting nature, and above all he would insist upon a training in mathematical sense, a development of the habit of mathematical thinking to such a degree that the prospective engineer shall be able to apply the fundamental principles as one to whom they have become his second nature.

Professor Slichter points out that, whereas engineering technology was founded chiefly on practice rather than on theoretical principles, it has now grown to be an investigative science of such proportions that few scientific productions now excel the engineering and technological treatises which come from the press. The need of the engineer is not so much that his mathematics shall be taught to him in some different way as that he shall have more mathematics. The engineer does not ask for better instruments or more difficult projects or more capital to conduct operations, but for more knowledge. It is a hopeful sign that many engineering institutions are now fostering some phase of investigative work. The chief requirement of the mathematical curriculum is that it shall be compact and stable. There is very little time for the engineering student to dally in mathematics with whims and fads and new schemes. Mathematics is to the engineer not merely a tool, but like physics and chemistry, it is to him a basal science, and should be made to appeal to his interest and his experience. He will forget his mathematics, to be sure, but he will forget his hydraulics also, and the one as easily as the other, if they are not both intrenched by strong ties of interest. Professor Slichter would plead for more opportunity for electives in mathematics in engineering courses but would insist that, so far as the teaching is concerned, any shortcomings in the engineering profession are quite as likely due to faults in the technological courses themselves as in the mathematical courses. 
Professor Williams recalls the fact that engineering a half century ago was merelyan art, but that it has now risen to the standing of a science as well as an art, and that from this wider point of view only does mathematics have a place in the training of the engineer. Engineering as a science is hampered by the trade school which naturally views it as an art only. The products of the trade school have little use for the mathematics of engineering. Both the trade school and the highly specialized technical school have their place. While the vast majority of those connected with engineering work possess and use a very limited mathematical training, yet we may well consider the mathematical equipment demanded by the man who is to climb to the top of his profession. Professor Williams maintains that what the trained engineer needs is not more formulas but a better understanding of principles and a stronger development of the reasoning power, so that he may indeed be able to think mathematically. To this end the mathematical teaching of the grammar school needs overhauling and next that of the high school, the implication being that too much formal and abstract work is now required, and too little development of independent thinking through the solution and interpretation of practical problems. Mathematics is a tool but it is to be used with intelligence and not in the blind following of rules; it is, so to speak, a living instrument which must respond like an intelligent servant. As to the question of increasing the mathematical requirements for engineering students, there is danger that this may work a disadvantage if this is done at the sacrifice of physics, chemistry, and the other sciences. Elective courses in mathematics should be provided in the engineering course but not till the fourth year, as few students are competent to elect intelligently before that time.

Professor Woods refers to the fact that while the best technological schools offer ample elective work in such mathematical courses as advanced calculus, least squares, differential equations of physics and mechanics, etc., yet their chief concern is not the development of mathematicians as such, but the training of engineers who shall be able to use mathematics in both practical and theoretical work. He has no patience with the professors of engineering who undertake to direct the work of mathematics in an engineering school. He believes that the teachers of mathematics must be mathematicians and that, while 
they should constantly connect their work with the concrete side, yet they must teach mathematics as mathematics. $\mathrm{He}$ believes that the teaching of mathematics, like all other teaching, is capable of improvement and that great improvement has been made and is now in progress, but he is not willing to admit that the teaching in this line is worse, or has been worse, than in other lines, as some engineers would seem to imply. The mathematical department delivers its product to the engineering department of the technical school, there to be subjected to the searching critical tests of further years of training, while the engineering department delivers its product to the outside world there to be swallowed up in the multitude, whose criticisms are aimed at the man himself rather than at those who have been his teachers. Professor Woods gave a clear exposition of the fundamental steps needed in the successful teaching of mathematics in its relation to its concrete applications and elicited much interest in the modification of the curriculum now being put into effect at the Massachusetts Institute of Technology.

Professor Swain is doubtful as to the worth of mathematical study other than as a means to an end - the development of a tool with which to do something. He is disposed to assign low value to mathematics as mere training in mental power, in comparison with some other branches of science. He would criticize the present teaching of mathematics as too ideal and abstract, looking for logical and theoretical results which conform to the demands of rigid demonstration regardless of common sense, clear observation, and good judgment. From the standpoint of the engineer, for whom mathematics is simply a useful tool, and whose training, therefore, should lead to power in handling the instrument, Professor Swain would point out that the present unsatisfactory results may be due in part to the lack of consecutiveness in the mathematical curriculum, especially in the latter part of the secondary course, which permits a lapse of from one to three years in the study of algebra, and also at other points in the curriculum allows the presentation of subjects in too isolated and incoherent fashion. He also asserts that too much attention is given to pure analysis and not enough to geometry. To the engineer, he says, geometry is all important. The geometric demonstration is grasped by the mind and comprehended step by step, while analysis is like a machine which transforms the data into the desired con- 
clusion by some occult process which the mind does not fully grasp. He would also revive the study of mental arithmetic and lay far more stress on all the mental processes of mathematical work. Finally he would discredit the lecture system of teaching mathematics, and would insist upon the Socratic method of question and cross-question in all class work, and would have the teaching of mathematics done by engineers or at least by men acquainted with the engineering applications of mathematics.

Professor Talbot discusses the mathematical training of engineering students from three points of view ; namely, theory, practice, and philosophy or interpretation. His contention is that a proper relative proportion of emphasis on these three phases is of more importance than the content or extent of the curriculum, provided the principles covered are really understood and intelligently interpreted and applied. He emphasizes the fact that we must deal with the average student and that it is only the exceptional student who is the mathematical genius, hence the methods of presentation must be such as to encourage and develop the great middle class of engineering students. Professor Talbot believes that, while formerly we may have carried theoretical and demonstrational processes to an extreme, we are now likely to swing to the other extreme, and let the student conclude that the facts are of chief importance and the proof of principles involves useless effort. He would insist that practice in analysis and formal demonstration is illuminating and developing to the mind, that even the old time mental arithmetic had its great educational value. Likewise, practice and drill work have their uses and abuses. To the average student the working of problems is illuminating and educative. Mathematics is a tool and the engineering student must acquire facility in its use and this demands drill and repetition. But the students who think that to accept facts and work problems is sufficient, and the instructors who think that illustration and practice alone constitute mathematical training or that mere laboratory methods suffice, are greatly mistaken. Again, there must be a direct connection between the theory and the philosophy of the subject to make the practice side serve its proper purpose. Professor Talbot would discourage the lecture method for engineering students and would select with great care the more advanced and complex courses which are offered, espe- 
cially those involving concepts lying beyond the student's experience.

President MeNair considers not so much the ideals which we might set up for the mathematical curricula of the engineering schools, as the nature of the actual demands which are made upon the graduates whom we turn out. The problem of the school is to meet the demand for men who can do something, men who can think in a logical and common sense way, men who are ready to accomplish results from the outset. The demand is not for highly trained mathematicians (however much we may think it is) but for men who can use a little mathematics and use it effectually as a tool. The danger is that the mathematical requirement may be too high. The mathematical concepts are difficult and it may be that we are expecting too much, too varied, and extensive attainments. The great thing is to gain ability to think correctly and logically about things, and in this respect the teacher of mathematics and the teacher of engineering have the same task before them. There is no better place than the mathematical class-room to develop logical thinking, but it should be done in connection with well selected concrete problems, rather than in the realm of abstract and theoretical considerations. The man who can take hold of a problem, analyze the data, put together the facts and reason logically to a sound conclusion, is already on the road to a successful career, and the teacher who is helping his students to attain such power is fulfilling his mission to the student who is to prepare for engineering.

Mr. Waddell refers to the teaching of mathematics to engineering students twenty years ago as sufficiently strenuous but far from satisfactory and finds little indication of radical improvement at the present time. He holds that the engineering student in his pure mathematical classes is not taught what the equations employed really mean, but that much of his work is a juggling with quantities to produce certain results, while it is left to the teacher of rational mechanics to bring out the reality of mathematics. He would advocate greater emphasis upon the interpretation of symbols used, the constant resort to graphical methods, expecially in analytics, the concrete application of all principles developed, especially in the calculus, a greater attention to the subject of descriptive geometry early in 
the engineering curriculum, and a thorough mastery of mechanics, whose foundation is mathematics and which underlies the superstructure of engineering. Mr. Waddell is strongly opposed to the lecture system of teaching mathematics to engineering students. Aside from introductory and concluding lectures, together with informal talks from time to time on the general trend of the subject, he would insist on the midnight oil and the damp towel as the necessary accessories for obtaining a real and comprehensive grasp of the subject for the average student. As to the instructional staff in engineering schools he would insist that the teachers of mathematics should also be engineers and should have a practical acquaintance with both rational and practical mechanics. And finally as to the extent of mathematical study for an engineer, while it is true that the actual use of analytic geometry, calculus, least squares, etc., rarely occurs in the practice of most engineers, yet the engineer's grasp of technical work depends upon his knowledge of these subjects and hence his mathematical foundation must be strong and substantial.

The general discussion was supported by Mr. C. F. Scott, Pittsburg, Pa., Dean C. M. Woodward, Washington University, Professor B. F. Groat, School of Mines, University of Minnesota, Professor S. M. Barton, University of the South, President C. S. Howe, Case School of Applied Science, Professor C. A. Waldo, Purdue University, Professor C. B Williams, Kalamazoo College, Mr. J. B. Webb, consulting engineer, Hoboken, N. J., Dean H. T. Eddy, College of Engineering, University of Minnesota, Professor D. F. Campbell, Armour Institute of Technology, Professor A. E. Haynes, College of Engineering, University of Minnesota, Professor E. W. Davis, University of Nebraska, Professor A. S. Hathaway, Rose Polytechnic Institute, and Professor E. V. Huntington, Harvard University.

Abstracts of these shorter addresses are not immediately available, but doubtless some of the more important utterances may be printed in connection with the formal papers in Science.

H. E. Slaught, Secretary of the Chicago Section. 